\title{
A Current Analysis of Black Head Football Coaches and Offensive Coordinators at the NCAA DI-FBS Level
}

\author{
Robert Turick and Trevor Bopp \\ University of Florida
}

\begin{abstract}
At the start of the 2015 college football season, 15 of the 128 NCAA DI-FBS programs took the field with a new head coach. Of note, is that none of the newly hired head coaches were Black, and 11 of the 15 hires climbed the coaching ranks on the offensive side of the ball. Given that $11.7 \%$ of the head coaching jobs in the league were available this offseason and none were filled by a Black coaching candidate could signify that the positive trends found after the 2010 season regarding the hiring of Black head football coaches (Bopp \& Sagas, 2012) may have plateaued, or even worse, declined. The purpose of this study was to ascertain if significant strides are being made in the promotion of Black coaches to head coach and offensive coordinator positions in college football, and evaluate how successful they have been in those positions. The findings of our study, which were interpreted using racial tasking (Bopp \& Sagas, 2014) as our theoretical lens, found that a) Black representation at the head coach and offensive coordinator position has plateaued, b) White head coaches statistically have higher winning percentages than their Black counterparts, c) White head coaches are afforded nearly a year more on average than Black head coaches to lead their programs, and d) that White offensive coordinators tend to manage more prolific passing teams (e.g., attempts, yards, and touchdowns) than their Black counterparts. The performance of Black coaches compared with their White counterparts has not favored Black coaches which may create prejudice in the mind of athletic administrators. Implications and suggestions for change are discussed.
\end{abstract}

Keywords: racial tasking, college football, discrimination, coaching

When the 2015 college football season began, 15 National Collegiate Athletic Association's (NCAA) Division I Football Bowl Subdivision (DI-FBS) programs had new head coaches. The 15 new head coaches were all White men that replaced other White men. Eight of the new hires were first-time head coaches, and within that group, five of them were offensive coordinators while the other one was an offensive position coach. The 2015 college football offseason continued the trend

The authors are with Tourism, Recreation \& Sport Management, University of Florida, Gainesville, FL. Address author correspondence to Robert Turick at turick44@ufl.edu. 
of administrators hiring offensive-minded coaches (Barnett, 2015; Dodd, 2015; Forde, 2015). According to Dodd (2015), the most recent hires around the country have been offensive coaches. They sell tickets, draw recruits and energize the fan base. Furthermore, in the 2015 college football offseason none of the six departing offensive-minded coaches that accepted a head coaching role was solely replaced by a Black coach; some teams appointed replacements with co-coordinator designations. Given that in 2015, 128 institutions participated in DI-FBS football, the fact that roughly $12 \%$ of the head coaching jobs in the league were available this past offseason and none were filled by a Black coach could signify that the positive trends found after the 2010 season regarding the hiring of Black coaches as head football coaches (Bopp \& Sagas, 2012) may have plateaued or declined over the past half-decade.

Further evidence that athletic directors have a preference for hiring offensiveminded coaches can be heard in the words of Maryland Athletic Director Ken Anderson at his press conference addressing the firing of former head coach Randy Edsall, "Fans want exciting, wide open offenses...Part of why we weren't successful these last six games is because we were not opening up the offense" (Big Ten Network, 2015). In addition, North Texas athletic director Rick Villarreal stated, after dismissing head coach Dan McCarney midseason, "we want someone who is going to be offensive-minded, can recruit and put us in position to be successful" (Vito, 2015).

The purpose of this study was to ascertain if significant strides are being made in the promotion of Black coaches to head coach and offensive coordinator positions in college football. To determine if significant strides were made an examination was conducted of the differences in the representation of Black and White coaches holding those aforementioned coaching positions over eight different seasons (2008-2015) at NCAA DI-FBS programs $(N=986)$. This study also examined the statistical offensive output of teams with Black offensive coordinators compared with their White counterparts over the same time frame in an attempt to demonstrate that on-field performance might serve to partially explain their underrepresentation in said coaching position. Likewise, an analysis of coaching records was completed to equate the on-field success via winning percentages of Blacks compared with Whites. Finally, an analysis of coaching tenures of Black and White head coaches hired during the 2003-2015 seasons was done to determine if athletic administrators are being fair in regards to offering equal tenure.

\section{Review of Literature}

As evidenced by the 2015 offseason in college football, the head coaching position is generally filled by individuals that have previously been a head coach elsewhere or by coordinators that administrators believe are ready to assume the role; most recently those individuals have had offensive backgrounds (Barnett, 2015; Dodd, 2015; Forde, 2015). Despite the success of Black head coaches at the professional level (Branham, 2008; Madden \& Ruther, 2011), Black coaches at the collegiate level have had a difficult time obtaining the head football coach position. Previous research conducted by Everhart and Chelladurai (1998) suggests that the applicants for vacant coaching positions are generally comprised predominantly of former athletes of that sport and thus it is reasonable to expect the racial composition 
of collegiate football coaching staffs to mirror the racial composition of football student-athletes.

Unfortunately, the mirroring of the racial composition in the sport with respect to coaches and players does not exist in college football. The most recent report from The Institute for Diversity and Ethics in Sport (TIDES), showed that in 2015 of all student-athletes in DI-FBS 53.4\% were Black, $41.4 \%$ were White, $2.4 \%$ were Asian/Pacific Islanders, $2.2 \%$ were Latino, and $0.6 \%$ were classified as "Other" (Lapchick \& Baker, 2016). As an organization, TIDES continues to educate the public regarding race and gender hiring practices in sport. TIDES works with Advocates for Athletic Equity (AAE), an organization that advocates for the promotion and/or hiring of ethnic minority coaches into positions of leadership at all levels of sport, to create report cards for racial and gender hiring practices in sport. The AAE was formerly known as Black Coaches and Administrators (BCA) which, similar to TIDES's report cards, published its own hiring report cards annually starting in 2004 (Harrison \& Yee, 2009). The last BCA Hiring Report Card, published in 2012, stated that between 1982 and 2011 there have been 546 head football coach openings at FBS schools. In those 29 years, a total of 50 African-Americans $(9.2 \%)$ were hired (Lapchick, Anjorin, \& Nickerson, 2012). There were a total of 39 head coach placements, at the FBS and FCS level, in 2012 which was the highest number since the report was started in 2004.

Former BCA Executive Director, Floyd Keith, maintains the organization's Hiring Report Cards "had a significant and lasting influence on this historic breakthrough" experienced by minority coaches in regards to obtaining employment as the head coach of college football programs (Lapchick et al., 2012, p. 6). Keith used the following facts to validate his opinion: 1) In the nine years since the publication of the first BCA Football Hiring Report Card, 61\% (28/46) of all the minority football coaches ever hired on the FBS level were hired; 2) From 2007-2012, $52 \%$ (24/46) of the minority head coach appointments occurred; and 3) From the 2003 football season, since the first 2004 BCA report card, there had been a $600 \%$ increase in the number of Football Bowl Subdivision (FBS) head football coaches of color from 3 to an all-time high of 18 at the start of 2012 season (Lapchick et al., 2012). Echoing this sentiment is current University of Michigan Director of Athletics, Warde Manuel, who stated that the BCA Hiring Report Cards helped to open the hiring process for head coaching positions in football because institutions knew their hiring process would be evaluated through the use of known criteria that were shared with everyone in collegiate athletics (Harrison \& Yee, 2009; Singer, Harrison, \& Bukstein, 2010). Finally, it should be noted that the number of minority hires started to decline in the final years of the Hiring Report Cards. The 2011-2012 Division I football hiring cycle provided 39 searches, which was the highest number of openings since the BCA hiring report card had been instituted. Only six of the thirty-nine appointments, or $15 \%$, were minority coaches compared with the 35\% of hires for 2010-2011 (Lapchick et al., 2012).

In an attempt to promote racial diversity among coaches, a recent suggestion from The National Association for Coaching Equity and Development has asked NCAA schools to adopt the Eddie Robinson Rule, which would require institutions to interview at least one minority candidate for all head-coaching and leadership positions before making their final hires (Medcalf, 2016). Akin to the NFL's Rooney Rule, the Eddie Robinson Rule is designed to encourage colleges 
and universities to interview at least one, preferably more than one, qualified racial and ethnic minority candidate in their final candidate pool for open head coaching and executive administrative positions (Medcalf, 2016). The Eddie Robinson Rule would finally be an answer from the field to previous calls from academicians for legislation that can facilitate social change and provide opportunity for colored people and women to obtain coaching and administrative roles in intercollegiate sport (Lapchick, 2010; O’Bryant, 2010).

\section{Framing the Current Discrepancy}

The difference between the number of Black student-athletes that participate in football to that of Black coaches is a well-researched area of race discrimination in sport. Cunningham and Sagas (2005) have opined that there is evidence of an "Old Boys Club" that serves as an access discrimination barrier. In addition, media influences (Cunningham \& Bopp, 2010), booster influences (Hughes \& Wright, 2003), and racial biases (Wong, 2002) have been offered as possible explanations for the discrepancy. Cunningham and Sagas (2005) studied the practice of homologous reproduction-hiring individuals that maintain similar surface-level characteristics - to explain negative impacts on the access of Black coaches into the coaching field, finding same-race hiring practices to be prevalent in intercollegiate athletics. They claim that with regards to advantageous social networks, rather than following the adage "who you know", it might be better said "who you know who is racially similar" (p. 157). Homologous reproduction might manifest in this case such that athletic administrators are still predominately White men, so they might be more likely to hire individuals who are also White men.

Anecdotally, when a team has an opening at the head coach position they traditionally fill the vacancy with a winning coach from a lower/equal program, a previously successful unemployed former head coach, or a successful coordinator. Internet websites and social media platforms are usually abuzz with lists of coaches they believe to be solid candidates for the open positions. Although many administrators are now using search firms to fill coach openings, it is fair to assume that administrators are cognizant of what those in the media are saying about perspective coaching candidates (Smith, 2012). Cunningham and Bopp (2010) studied the way in which the media discussed new coaching hires and found that the media generally portrays White coaches as being more knowledgeable about the strategy of the game than their Black counterparts, while Black coaches were viewed as solid recruiters that can relate well with potential and current studentathletes. Should this sentiment still hold true today, it would serve as an indicator that the sad reality of the industry is that Black coaches are not viewed as solid game planners or signal callers.

Similarly, boosters and other athletic supporters might let it be known whom they believe the next head coach should be. While their input might not be used, the impact of outside stakeholders (e.g., alumni, boosters, fans, etc.) should not be disregarded, as the hiring of Black head coaches is not solely dependent upon playing/coaching history and social networks. At the college level of play, some schools might fear that a Black head coach would potentially damage future contributions and support (Wong, 2002). A recent case study that depicts booster bias against a Black head coaching hire occurred at the University of Texas. The program hired 
Charlie Strong, a Black man, to serve as the head coach of their football team, which was not received well by longtime booster Red McCombs. McCombs commented that Strong (37-15 as a head coach at the University of Louisville) would make a great position coach or coordinator, but that he did not belong at one of the three most powerful university programs in the world (Olson, 2014).

Furthermore, it is important to investigate whether a racial bias exists in the firing of college football coaches. According to Kopkin (2014), if decision-makers are discriminating against Black head coaches when deciding whether to retain them, these racial attitudes are most likely present in their hiring decisions as well. It is important to assess the racial composition of the hiring committee and decisionmakers because the demographic makeup of the search committee, particularly the racial diversity of committee members, is an integral aspect of understanding and analyzing the head coach hiring process in college football (Singer, Harrison, \& Bukstein, 2010). Interestingly, it is actually to the athletic department's benefit to be demographically diverse because athletic departments that are demographically diverse and whose membership is strongly committed to diversity realize more positive outcomes (Cunningham, 2008). In addition to observing and reporting that Black coaches are not being given head coaching opportunities, an effort should be made to ensure that those who are getting opportunities to become head coaches are given a fair amount of time, in terms of tenure at an institution, to succeed and achieve the goals of all relevant stakeholders. This is important because it allows for coaches to implement their coaching schemes and philosophies while also trying to change the culture of a program to one that reflects how they want the program to look (Frankovelgia, 2010; Vannini, 2015).

The amount of time afforded to head coaches is subjective as it is the prerogative of individual institutions, but examining coaching tenures against the industry standard as well as the views of established coaching professionals, provides a context in which to better understand the current landscape of head coaching. A total of 265 head coaching hires of White and Black coaches occurred from 2003-2015 with the average coaching tenure lasting 4.32 years. Comparatively, Rocky Long, current San Diego State University Head Football Coach, stated:

"Now, the (schools) hire new coaches, they expect you to fix it (the program) in a day. You don't fix programs in a day. It takes you six, seven years to fix a program. That's my belief. ..." (Vannini, 2015, para. 7).

Essentially, it can be argued that a coach deserves at least 4 years (based on the industry norm), potentially as many as 7 years (based on the opinion of at least one coaching professional), to succeed at an institution.

\section{Black Coaches and Athletes Career Aspirations}

The potential lack of promotion of Black assistant coaches to the head coach, and subsequent coordinator positions, is only an issue if the attainment of those positions is something that Black coaches and players aspire toward. Cunningham, Bruening, and Straub (2006) found that Blacks did not differ from Whites in their desire to become a head coach. In addition, they found that Black coaches perceived discrimination as a barrier to obtaining a head coach position and that Black coaches experienced greater occupational turnover than their White counterparts. Just as 
Black assistant coaches aspire toward the position of head football coach, so too do Black student-athlete football players.

Some potential reasons that have been offered to explain why Whites hold more coaching positions include that Black players are more focused on their professional opportunities and that they are less interested in coaching than their White counterparts (Cunningham, 2003; Eitzen. 2014); which would allow their White counterparts to enter into the coaching profession earlier. In opposition to that belief, Park, Tomasini, and Shields (2010) surveyed 210 student-athletes and found that Black players were more certain than their White peers they could obtain a coaching job in the professional ranks following their playing careers. Over two-thirds $(68.6 \%)$ of Black student-athletes sampled stated they had an interest in the coaching profession, an interest level virtually equivalent to their White teammates (67.6\%). These findings were similar to Everhart and Chelladurai (2004) who determined race did not have any effect on one's desire to coach, which was contradictory to Cunningham's (2003) study which found approximately one third of Black football student-athletes had an interest in coaching, a figure significantly less than their White peers. Despite somewhat mixed results regarding the career coaching aspirations of Black student-athletes, it is evident that interest is not positively associated with achievement among potential Black head coaches.

During the 2015 season, $53.4 \%$ of DI-FBS players were Black, $27.1 \%$ of DI-FBS assistant coaches were Black, and $10.2 \%$ of DI-FBS head coaches were Black (Lapchick \& Baker, 2016). These numbers show that the number of head coaches do not reflect the number of assistant coaches or players, and that the number of assistant coaches does not reflect the number of players. Despite the fact that Black players comprise more than half $(53.4 \%)$ of the student-athletes participating in DI-FBS, only a little more than one-quarter $(27.1 \%)$ of assistant coaches and around one-tenth $(10.2 \%)$ of head coaches are Black.

\section{Theoretical Background}

A variety of theories and concepts have been suggested by previous researchers to explain the underrepresentation of Black head coaches and offensive coordinators in college football, such as (1) homologous reproduction, which refers to a process by which individuals hire people that are similar or the same as them (Cunningham \& Sagas, 2005); (2) positional segregation, which refers to the potential that few Black men have the opportunity to be hired as coaches because a high percentage of college coaches and administrators are recruited from central positions (Kamphoff \& Gill, 2008); (3) role congruity theory, which can explain how potential prejudices associated with Black coaches might be incongruent with what individuals perceive to be the attributes necessary to hold a head coaching position (Eagly \& Karau, 2002); and (4) stacking, which is the assigning of athletes to certain playing positions based on assumptions regarding one's athletic ability and race (Sack, Singh, \& Thiel, 2005). Three additional propositions were set forth by Cunningham, Sagas, and Ashley (2001) to explain the underrepresentation of Blacks in head coaching positions: (a) Blacks are constrained by societal and occupational factors, such as hiring discrimination; (b) Blacks leave the coaching profession earlier than their White counterparts; and (c) Blacks do not view coaching as a primary career path. 
Our approach in this study is to use a new form of racial discrimination, racial tasking, to interpret current hiring trends and responsibilities of coaches. Bopp and Sagas (2012) found that stacking continues to remain a potential influence, and adversely so for Blacks, on the career coaching outcomes of current and future players. A recent extension of the stacking literature, to include racial tasking, was recently discussed by Bopp and Sagas (2014). They defined racial tasking in sport as a function of one's prejudice toward a minority athlete's capabilities, both mental and physical, to perform. Accordingly, the tasks athletes are asked to perform are dependent upon the athlete's race and vary despite occupying the same playing position (p. 140). Extending racial tasking to encompass coaches, racial tasking could serve to explain one's prejudice toward a minority coach's capabilities, both mental and physical, to perform. Just as the Black quarterbacks (tasked with running the ball more often than White quarterbacks) and White quarterbacks (tasked with throwing the ball more often than Black quarterbacks) were used differently by their coaches based on race (Bopp \& Sagas, 2014), Black and White coaches might be used and viewed differently by athletic administrators as a result of their race.

The differences in how coaches are perceived due to their race might explain why the media portrays White coaches to have greater football knowledge than Blacks (Cunningham \& Bopp, 2010); because Black coaches are placed into positions where strategy/game plan development are not a function of their job. Advancing the notion that Black coaches may be hurt by the recruiter role, Day (2015) recently found that Black coaches' careers, compared with their White counterparts, are harmed more by occupying noncentral coaching positions. If Black coaches are being hired into positions with a recruiting focus and Whites are obtaining positions that focus more with strategizing and game planning, then it stands to reason that Black coaches might not have the same understanding or knowledge of the game as White coaches. Finch, McDowell, and Sagas (2010) found that the efforts of Black players and coaches to fight the stereotypes ascribed to them has not gone well as they continue to be disregarded in the hiring process, which would seemingly perpetuate the stereotype that they have limited football knowledge and thus establishes a ceiling for how high (or low) administrators perceive they should be able to climb.

\section{The Current Study}

The current investigation was designed with the aim of identifying if significant strides have been made in regards to Black coaches achieving head coach and offensive coordinator positions; as well as to expand the work on racial tasking (Bopp and Sagas, 2014) as a new form of racial stacking or discrimination. Specifically, we examined the 2008-2015 seasons to determine trends in the representation of Black coaches at the head coach and offensive coordinator position, the on-field success (i.e., win-loss records) variance of coaches by race, and the difference in offensive output of a team based on the race of that team's offensive coordinator. Lastly, we examined coaching tenures in college football from 2003-2015 to determine if Black head coaches are being given the same amount of time as their White counterparts to succeed. The following research questions guided this examination:

RQ1: Is the representation of Black head coaches in college football at the DI-FBS level trending up, down, or remaining constant between 2008-2015? 
RQ2: Is the representation of Black offensive coordinators in college football at the DI-FBS level trending up, down, or remaining constant between 2008-2015?

RQ3: Is there a significant difference in on-field winning percentage (e.g., win-loss records) of head coaches based on race?

RQ4: Is there a significant difference in the offensive output of a team (e.g., total points scored in a season, total passing yards in a season, total rushing yards in a season) based on the race of the team's offensive coordinator?

RQ5: Are White head coaches afforded more time than their Black counterparts, in terms of tenure at an institution, to succeed?

\section{Data Collection and Analysis}

Data were obtained through accessing the official websites of all NCAA DI-FBS programs from 2008-20015 and opening their archive pages $(N=986)$. Official roster biographies and statistics from the 2008-2015 NCAA DI-FBS seasons resulted in 1,972 head coaches and offensive coordinators, of which only 1,930 were eligible based on the criteria that the coach was either White or Black. Of the resultant eligible head coaches $(N=961), 98$ were identified as Black and 863 as White; of the resultant eligible offensive coordinators $(N=969), 72$ were identified as Black and 897 as White. In reference to the offensive coordinator position, at some institutions there is no offensive coordinator, because the head coach calls the plays, so in those instances the head coach was listed as the offensive coordinator at those institutions. In addition, some institutions have an offensive coordinator in place but the head coach still calls the plays, thus the offensive coordinator does not fulfill the traditional offensive coordinator role. Since we are unable to learn the dynamics of play calling for all DI-FBS programs, and we sought to maintain consistency, the head coach and offensive coordinator at all institutions were recorded based on their assigned official positions. Lastly, our data collection does not account for interim head coaches, except in rare cases where the replacement was in place for the bulk of the season. The majority of interim hires only are in place for a few games, traditionally one, and thus do not give those coaches a representative opportunity to reflect their abilities.

Archived web pages provided links to past media guides which were used to learn the race of the head coach and offensive coordinator, as well as compile the offensive statistical information from past seasons (e.g., points, total touchdowns, pass attempts, passing yards, passing touchdowns, rush attempts, rushing yards, and rushing touchdowns). In addition, the College Sport Racial and Gender Report Cards published by TIDES were used to assist in the recording of coaches by race. Since not all of the NCAA DI-FBS programs are represented in the report, the researchers added the coaches that had been excluded from the report and adjusted for year-to-year discrepancies in the report. Furthermore, the win-loss record of each team by season was recorded for analysis as the on-field success variable. To answer research question five, the name and race of all head coaches that were hired from 2003-2015 were compiled in a separate excel spreadsheet. Once the name and race of each head coaching hire was recorded in excel, researchers used internet searches to determine the coach's tenure at that institution. 


\section{Results}

The first research question (RQ1) sought to determine if the positive trend of Black coaches obtaining head coaching positions that Bopp and Sagas (2012) found, and the last BCA hiring report card highlighted (Lapchick et al., 2012), after the 2010 football season had plateaued, fallen, or risen. This study incorporated the 2015 college football season into an already complete data set to provide eight years (2008-2015) of football statistics and coaching movement. The data were viewed as crosstab output (see Table 1) and the results indicated that the percentage of Black head coaches in college football has increased from 5\% (6 of 120 programs) in 2008-10.16\% (13 of 128 programs) in 2015. In reference to the previous findings by Bopp and Sagas (2012) that the hiring of Black head coaches was trending in a positive direction, our results indicate that those positive gains seem to have plateaued over the past half-decade. In 2010, Black representation at the head coach profession accounted for 13 of those positions which is identical to the 2015 value. Black head coaching representation in DI-FBS peaked at 17 in 2011 and has declined in the subsequent years to return to the 2010 value. This plateau effect has occurred despite the fact that the number of teams participating in college football at the DI-FBS level has increased over the past five years from 120 to 128 programs. In total, Black coaches held less than 10\% (9.93\%; 98 of 986 programs) of the total head coach positions from 2008-2015.

Similar to RQ1, the second research question (RQ2) examined if Black coaches were obtaining the offensive coordinator position. The data were viewed as crosstab output (see Table 2) and the results indicated that the percentage of Black offensive coordinators in college football has decreased from $9.17 \%$ (11 of 120 programs) in $2008-6.25 \%$ (8 of 128 programs) in 2015. Despite the addition of eight teams to the FBS ranks over the past five years, the amount of Black coaches holding offensive coordinator positions has decreased. In total, Black coaches held 7.3\% (72 of 986 programs) of the offensive coordinator positions from 2008-2015; which averages to 9 per season.

In an attempt to show competitive equality, the third research question (RQ3) aimed to determine if a statistically significant difference exists between Black and White head coaches in terms of their on-field success from 2008-2015 (N =961). An ANOVA test was used to address this question (see Table 3). The

Table 1 Black Representation at the Head Coach Position in College Football (\% in parenthesis)

\begin{tabular}{lccccccccc}
\hline Year & $\mathbf{2 0 0 8}$ & $\mathbf{2 0 0 9}$ & $\mathbf{2 0 1 0}$ & $\mathbf{2 0 1 1}$ & $\mathbf{2 0 1 2}$ & $\mathbf{2 0 1 3}$ & $\mathbf{2 0 1 4}$ & $\mathbf{2 0 1 5}$ & Total \\
\hline Black & 6 & 7 & 13 & 17 & 15 & 14 & 13 & 13 & 98 \\
& $(5.00)$ & $(5.83)$ & $(10.83)$ & $(14.17)$ & $(12.10)$ & $(11.11)$ & $(10.16)$ & $(10.16)$ & $(9.94)$ \\
White & 111 & 110 & 104 & 101 & 105 & 109 & 112 & 111 & 863 \\
& $(92.50)$ & $(91.67)$ & $(86.67)$ & $(84.17)$ & $(84.68)$ & $(86.50)$ & $(87.50)$ & $(86.72)$ & $(87.53)$ \\
Other & 3 & 3 & 3 & 2 & 4 & 3 & 3 & 4 & 25 \\
& $(2.50)$ & $(2.50)$ & $(2.50)$ & $(1.67)$ & $(3.23)$ & $(2.38)$ & $(2.34)$ & $(3.13)$ & $(2.54)$ \\
Total & 120 & 120 & 120 & 120 & 124 & 126 & 128 & 128 & 986 \\
\hline
\end{tabular}


Table 2 Black Representation at the Offensive Coordinator Position in College Football (\% in parenthesis)

\begin{tabular}{lccccccccc}
\hline Year & $\mathbf{2 0 0 8}$ & $\mathbf{2 0 0 9}$ & $\mathbf{2 0 1 0}$ & $\mathbf{2 0 1 1}$ & $\mathbf{2 0 1 2}$ & $\mathbf{2 0 1 3}$ & $\mathbf{2 0 1 4}$ & $\mathbf{2 0 1 5}$ & Total \\
\hline Black & 11 & 10 & 7 & 8 & 11 & 10 & 7 & 8 & 72 \\
& $(9.17)$ & $(8.33)$ & $(5.83)$ & $(6.67)$ & $(8.87)$ & $(7.94)$ & $(5.47)$ & $(6.25)$ & $(7.30)$ \\
White & 106 & 107 & 111 & 111 & 112 & 114 & 118 & 118 & 897 \\
& $(88.33)$ & $(89.17)$ & $(92.50)$ & $(92.50)$ & $(90.32)$ & $(90.48)$ & $(92.19)$ & $(92.19)$ & $(90.97)$ \\
Other & 3 & 3 & 2 & 1 & 1 & 2 & 3 & 2 & 17 \\
& $(2.50)$ & $(2.50)$ & $(1.67)$ & $(0.83)$ & $(0.80)$ & $(1.59)$ & $(2.34)$ & $(1.56)$ & $(1.72)$ \\
Total & 120 & 120 & 120 & 120 & 124 & 126 & 128 & 128 & 986 \\
\hline
\end{tabular}

Table 3 Winning Percentages of Head Coaches by Race

\begin{tabular}{lccc}
\hline Race & N & M & SD \\
\hline Black & 98 & .41 & .02 \\
White & 863 & .53 & .01 \\
\hline
\end{tabular}

results of our ANOVA test revealed that there is a statistically significant difference between win percentage by White $(M=.53, S D=.22)$ and Black $(M=.41, S D=$ $.25)$ head coaches based on race $F(1,959)=26.549, p<.001, \eta^{2}=.027$. White head coaches won a higher percentage of their games per season $(53 \%)$ than their Black counterparts $(41 \%)$.

The fourth research question (RQ4) examined the statistical output of teams (e.g., total points, total touchdowns, pass attempts, passing yards, passing touchdowns, rush attempts, rushing yards, and rushing touchdowns) based on the race of that team's offensive coordinator. Once all the data were collected a MANCOVA test was conducted - controlling for number of plays - to determine if any statistical differences exist. The reason that the researchers' controlled for the number of plays called is because we wanted to control for scheme differences that would bias certain teams that run up-tempo offenses.

The results indicate that five statistically significant differences exist (see Table 4 ) at the offensive coordinator level based on race. Differences in the number of passing attempts $F(1,966)=5.833, p=.016, \eta^{2}=.006$; passing yards $F(1,966)$ $=8.809, p=.003, \eta^{2}=.009$; passing touchdowns $F(1,966)=6.625, p=.010, \eta^{2}$ $=.007$; rushing attempts $F(1,966)=5.865, p=.016, \eta^{2}=.006$; and rushing yards $F(1,966)=3.923, p=.048, \eta^{2}=.004$ per season were found to be statistically significant.

In regards to passing the ball, teams with a White offensive coordinator averaged more passes in a season $(E M M=404.26, S E=2.66)$ than teams with a Black offensive coordinator $(E M M=380.71, S E=9.38)$; teams with a White offensive coordinator passed for more yards on average per season $(E M M=2912.92, S E$ $=21.09)$ than teams with a Black offensive coordinator $(E M M=2683.30, S E=$ 74.43); and teams with a White offensive coordinator had more touchdown passes on average per season $(E M M=20.86, S E=.23)$ than teams with a Black offensive coordinator $(E M M=18.65, S E=.83)$. 
Table 4 Offensive Coordinator Seasonal Output: 2008-2015 Seasons

\begin{tabular}{lccccccc}
\hline Statistic & Black & Std. Error & White & Std. Error & $\mathbf{F}$ & Sig. & $\eta^{2}$ \\
\hline Pass Attempts & 380.71 & 9.38 & 404.26 & 2.66 & 5.833 & .016 & .006 \\
Passing Yards & 2683.30 & 74.43 & 2912.92 & 21.09 & 8.809 & .003 & .009 \\
Passing TDs & 18.65 & .83 & 20.86 & .23 & 6.625 & .010 & .007 \\
Rushing Attempts & 508.07 & 9.40 & 484.42 & 2.66 & 5.865 & .016 & .006 \\
Rushing Yards & 2274.14 & 77.50 & 2114.60 & 21.96 & 3.923 & .048 & .004 \\
\hline
\end{tabular}

In regards to running the ball, teams with a Black offensive coordinator averaged more rush attempts per season $(E M M=508.07, S E=9.40)$ than teams with a White offensive coordinator $(E M M=484.42, S E=2.66)$, and teams with a Black offensive coordinator rushed for more yards on average per season $(E M M$ $=2274.14, S E=77.50)$ than teams with a White offensive coordinator $(E M M=$ 2114.60, $S E=21.96)$.

Our fifth research question (RQ5) aimed to determine if White head coaches are provided with more time to succeed than their Black counterparts. A total of $265(N=265)$ head coaching hires of a White and Black coaches occurred from 2003-2015; of which 230 were White $(n=230)$ and 35 were Black $(n=35)$. We analyzed the tenure of those newly hired coaches to determine if there was a significant difference regarding the tenure allotted to each coach. In addition, we compared the first-year winning percentage of the head coaches by race (see Table 5). A MANOVA test revealed that there is a statistically significant difference between the race of a head coach and his tenure at an institution $\mathrm{F}(1,263)=4.897$, $p=.028, \eta^{2}=.018$. White head coaches $(M=4.44, S D=2.42)$ spent more time at an institution compared with Black head coaches $(M=3.51, S D=1.27)$. Similarly, the MANOVA test revealed that there is a statistically significant difference between the race of a head coach and his first-year winning percentage at a new institution, $\mathrm{F}(1,263)=6.316, p=.013, \eta^{2}=.023$. The results show that White head coaches $(M=.44, S D=.23)$ had a statistically significantly higher winning percentage in their first season at a new school compared with Black head coaches $(M=.34, S D$ $=.22$ ). In summation, the results to RQ5 show that White head coaches are serving as the head football coach at institutions for longer and that they are winning more games in their first season than their Black counterparts.

\section{Discussion}

Over the past 15 years, a number of studies investigating race discrimination at the college football head coaching position found that a variety of barriers exist that may prevent Black coaches from obtaining head coaching positions (Bopp \& Sagas, 2012; Cunningham, Bruening, \& Straub, 2006; Park, Tomasini, \& Shields, 2010). The identification of these barriers was established by researchers who examined this issue through a variety of theories and conceptual frameworks such as homologous reproduction (Cunningham \& Sagas, 2005), positional segregation (Kamphoff \& Gill, 2008), role congruity theory (Eagly \& Karau, 2002), and 
Table 5 Newly Hired Coaching Tenures from 2003-2015

\begin{tabular}{lccccc}
\hline Race & $\mathbf{N}$ & Mean & SD & First Year Win \% & SD \\
\hline Black & 35 & 3.51 & 1.27 & .34 & .22 \\
White & 230 & 4.44 & 2.42 & .44 & .23 \\
\hline
\end{tabular}

stacking (Sack, Singh, \& Thiel, 2005). The purpose of this study was to ascertain if racial tasking (Bopp \& Sagas, 2014) could be used to interpret the lack of Black coaches at the head coach and offensive coordinator positions in college football, the differences in tenure for head coaches based on race, and the offensive output of teams based of the race of their offensive coordinator. To determine its potential application, the race of head coaches and offensive coordinators, coaching tenures, and offensive output were examined.

In alignment with the findings of previous research, the results of this study found that Black coaches continue to be underrepresented at the head coach and offensive coordinator positions. This finding occurred despite national and organizational support from the NCAA in the form of its Champion Forum (NCAA, 2016), which provides a unique yearlong professional development opportunity for current minority college football coaches to learn a realistic view of the role of and preparation it takes to become a head football coach in the college game, and the continued expansion at the DI-FBS level. Black coaches held less than 10\% $(9.93 \%)$ of the total head coach positions and $7 \%$ of the offensive coordinator positions from 2008-2015. Thus, our findings mirror the last BCA Hiring Report Card which stated that between 1982 and 2011 a total of 50 African-Americans (9.2\%) head coaches were hired (Lapchick et al., 2012).

Understanding this paltry representation under the tenets of racial tasking, the fact that Black coaches have not received many head coaching opportunities could indicate that those involved in the hiring process may have a prejudice regarding a Black coach's ability to perform successfully in those roles, or that hiring committees and/or administrators view Black coaches differently solely based on race. Also potentially noteworthy, in regards to this finding, is the comparison summary that more Black coaches occupy the head coach position than they do the offensive coordinator role. Consider the last three seasons, 2013-2015, 40 Black coaches held the head coach title compared with 25 holding the offensive coordinator title. Since the coordinator position often serves as a stepping-stone position, this result does not promote an optimism that future Black head coaching candidates are being groomed at the offensive coordinator level.

Our findings add to the existing body of literature regarding race discrimination in college football by highlighting, for researchers and coaching advocacy groups, a potential issue that helps to explain the discrepancy in the hiring of Black head coaches. The fact that recent trends in coaching hires tend to support the notion that athletic administrators are searching for offensive-minded coaches (Barnett, 2015; Dodd, 2015; Forde, 2015) from an applicant pool devoid of many Black candidates may explain the low number of Black head coaches in college football. In addition, the fact that administrators have been hiring offensive-minded coaches suggests that having that background is viewed as important in their eyes. Black 
coaches have not obtained many of the offensive coordinator positions, which may hurt how they are viewed by athletic administrators. Success as an offensive coordinator might be perceived as the precursor to success as a head coach, so the lack of Black offensive coordinators would potentially limit the lack of perceived successful head coaching candidates of color.

The lack of Black head coaches and offensive coordinators in college football provides evidence that social change needs to occur. Fostering social change can be accomplished through creating perspective-altering experiences that allow people (e.g., athletic decision makers) to understand the effects of social injustice (Melton, 2015). Consider for instance what the lack of Black head coaching examples implies to Black student-athletes. Melton (2015) stated that "instances of social injustice are commonplace in college sport and negatively affect athletes, coaches, administrators and staff" (p. 2). The fact that Black student-athletes do not see a lot of Black coaches may hinder their belief that a coaching career is realistic for them. In addition, this potential hindrance in career coaching aspirations could perpetuate the continued trend of Black assistant coaches being tasked with the role of "recruiter" or "relatable coach'; positions that require more time and effort to progress through the coaching ranks.

In addition to highlighting the lack of Black coaches at the head coach and offensive coordinator positions, the results of our study offer four inferences about the current trend of hiring Black head coaches and offensive coordinators in college football. The first is that White head coaches statistically have higher winning percentages $(53.14 \%)$ than their Black counterparts $(40.92 \%)$. The discrepancy in winning percentage may influence the confidence athletic administrators have in a Black coach's ability to successfully perform at the head coach position, potentially leading to a racial bias against the hiring of Black coaches. Since the sample size for Black head coaches-which traditionally hold slightly less than ten percent of head coaching positions - is considerably smaller than that of White head coaches, future research should focus on investigating why those Black head coaches who have gotten opportunities have not succeeded.

One potential explanation could be that Black coaches are not groomed to excel in that role as they navigate up the coaching ladder. Support for this potential explanation can be witnessed in media depictions of new coaching hires, in which White coaches are presented as more knowledgeable than their Black counterparts (Cunningham \& Bopp, 2010). It could be argued that head coaches of college football teams have a responsibility to develop their players and their assistant coaches. The lack of development of Black assistant coaches, or the perceived lack of development by athletic administrators, would hinder the ability of Black coaches to cultivate the skills necessary to successfully transition into the head coach role. If Black assistants are tasked with recruiting, that might show prejudice from head coaches toward their ability to be part of game preparation. In addition, the findings of the Cunningham and Bopp (2010) research, provide supportive evidence of racial tasking of assistant coaches (e.g., White coaches are strategic game planners and Black coaches are great recruiters), which would extend to this study. Thus, for those assistants interested in obtaining a head coach position, they should be trained accordingly, regardless of race in an effort to alleviate any perceived mental prejudices of athletic administrators. 
The second inference that emerged from this study, and explains the findings of Research Questions 3 and 5, is that White head coaches are afforded nearly a full year more (0.93 years) on average than Black head coaches to lead their programs, which may show a racial basis. It should also be noted that the tenure of Black head coaches falls short of both the industry standard for new hires from 2003-2015 (4.32 years) as well as anecdotal evidence suggesting that coaches may need up to six or seven years to fix a program (Vannini, 2015). The fact that athletic administrators are providing unequal tenure opportunities to head coaches, potentially based on race, provides evidence that a prejudice regarding a Black head coach's capabilities to perform successfully at the position may exist. White head coaches are more successful than Black head coaches on the field (wining 53.14\% v 40.92\%) which may be attributed to the fact that White coaches are given an additional year to implement their schemes, develop players, and establish their desired culture. Conversely, the fact that Black head coaches are afforded one fewer year than White head coaches might provide reason for this win discrepancy.

An incoming coach's first recruiting class is generally comprised of both his own players and those that were signed/committed to the previous coaching regimen. Furthermore, considering that recruiting is a year-round task, the first recruiting class is generally considered to not represent that coach's ability. Consider the words of current San Diego State University Head Football Coach Rocky Long (Vannini, 2015, para. 7):

You have to recruit players that fit your personality and schemes, and guess what? They're not any good as freshmen. They're not. It's unfair to them. You have to wait until they're third- and fourth-year guys before you can see if they can play or not. ... It takes us three years to have a good player out there.

If a coach is replaced after three or four seasons it is unlikely that few, if any, of the players that he has brought to campus are upper classmen yet. Replacing a Black coach before he has four seasons to recruit and develop players might be considered unfair because the players that he has recruited are just entering their junior seasons, whereas his White counterpart is getting that additional fourth year.

Consider Tyronne Willingham's tenure at Notre Dame as a case study that exemplifies the fact that Black coaches might not receive equal tenure compared with their White counterparts, and the importance of giving a coach time to develop his own players. Willingham (Black) was fired by Notre Dame after three seasons (2002-2004) in which he compiled a 21-15 record. His predecessor, Bob Davie (White), had a nearly identical record after three seasons (21-16; 1997-1999) but was retained for two more seasons (2000-2001). Willingham's replacement, Charlie Weis (White), compiled a 22-15 record in his first three seasons at Notre Dame (2005-2007) and was similarly retained as head coach for two more seasons (2008-2009). Weis experienced his best seasons at the beginning of his tenure at Notre Dame winning 19 games in his first two years; with upperclassmen that Willingham had recruited during his brief tenure as coach.

In addition to receiving less time to coach at a program, Black head coaches are starting off their tenure at an institution with a significantly lower winning percentage than their White counterparts. White head coaches won $44.40 \%$ of their games in the first season at a new school compared with Black head coaches which won 
almost 34\% (33.99) of their games in the first season at a new school. In a traditional 12 games season, neither coach is making a bowl game in their first season, but the White head coach is finishing with 5.33 wins (a 5-7, almost bowl eligible record) and the Black head coach is finishing with 4.08 wins (a 4-8 record). This discrepancy could speak to the quality of inherited programs of Black head coaches.

An emerging line of research has advanced the concept of the Glass Cliff which should be extended to include investigating race discrimination. The Glass Cliff suggests that certain leadership positions are relatively risky or precarious since they are more likely to involve management of organizational units that are in crisis (Ryan \& Haslam, 2005). An argument can be made that if Black coaches are more likely to be selected for positions with a higher likelihood of failure, this can serve to reinforce preexisting stereotypes regarding their ability to be leaders. One of the pillars of racial tasking is looking at how coaches are used differently based on race. In terms of the Glass Cliff, Black and White coaches might be used and viewed differently by athletic administrators as a result of their race; Black coaches could serve as temporary placeholders during times of crisis. Evidence that Black coaches accept bad jobs, supporting our Glass Cliff proposition, and are given little time to fix them has been previously suggested (Gemmell, 2012). Furthermore, the discrepancy in first year winning percentage supports the notion that Black coaches are not always inheriting talented programs. Previous research into the Glass Cliff has focused on Women (Brescoll, Dawson, \& Uhlmann, 2010; Ryan, Haslam, Hersby, Bongiorno, \& Renata, 2011), so race is an area that merits consideration.

Considering that head coaching vacancies are often filled by coordinators or past head coaches, the fact that Black coaches are not obtaining more offensive coordinator positions is concerning when discussing the future promotion of Black coaches to the head coaching position. In addition, this issue is even more concerning if you listen to former Black head coaches like the University of Colorado's Jon Embree, an alum of that institution, who was fired in the second year of a five-year contract. At his farewell press conference, he said, "You know we (Black head coaches) don't get opportunities. At the end of the day, you're fired and that's it. Right, wrong or indifferent. Tyrone Willingham was the only one who got fired and got hired again. We get bad jobs and no time to fix them" (Gemmell, 2012, para. 7). Embree's words speak to the Glass Cliff concept and to the fact that Black head coaches that are fired do not usually receive a second head coaching opportunity, so the idea of former Black head coaches being a retrend hire is highly unlikely. This issue is not specific only to college football, as Black coaches in the NFL are experiencing the same issues. Harrison and Bukstein (2014) found that NFL teams have historically been reluctant to hire a non-White individual for a head coach, offensive coordinator or defensive coordinator position after a non-White individual has previously separated from a head coach position in the NFL. It appears, at least anecdotally, that the same barriers are present for Black college coaches.

The third inference that emerged from this study is Black representation at the head coach and offensive coordinator position has plateaued. Despite the addition of eight teams from the 2008 to the 2015 season the number of Black coaches occupying the role of head coach or offensive coordinator has remained stagnant. Black head coaches saw increased opportunities in 2010 - which is the main reason why the number of Black head coaches in college football has increased from $5 \%$ (6 of 120 programs) in 2008-10.16\% (13 of 128 programs) in 2015-but that was 
not the beginning of a trend. Black offensive coordinators have not obtained the role of offensive coordinator at an increasing pace; averaging nine Black offensive coordinators per season from 2008-2015. One possible explanation for the plateau effect could be the disappearance of the BCA. Before the BCA Hiring Report Cards there were very few ethnic minority hires in college football. However, during the existence of this organization positive gains were made by minority coaches in obtaining head coach positions. The research and accountability published and purported by the BCA likely played a role in perpetuating this change. Unfortunately, since the BCA Hiring Report Cards are no longer published, minority coaches no longer have the assurance that institutions are engaging in fair hiring practices, like Warde Manuel referenced, when attempting to fill vacancies (Singer, Harrison, \& Bukstein, 2010). Thus, the lack of oversight organizations may in part explain why there has been a plateau of ethnic minority hires since 2010 .

Finally, the fourth inference that emerged from this study is that White offensive coordinators tend to have more prolific passing numbers (e.g., attempts, yards, and touchdowns) than their Black counterparts which tend to have better rushing numbers (e.g., attempts and yards). The fact that White offensive coordinators orchestrate more prolific passing games may give them an advantage when they are being considered for head coaching positions. The proverbial adage that "offense sells tickets" is in accordance with the continuing trend of administrators hiring offensive-minded coaches (Barnett, 2015; Forde, 2015). White offensive coordinators were found to have statistically superior passing numbers as they attempt more passes, throw for more yards, and throw for more touchdowns in a season when compared with Black offensive coordinators. Decision-makers are essentially left to choose between the aerial game that White offensive coordinators orchestrate or the proverbial "three-yards-and-a-cloud-of-dust" game that Black offensive coordinators orchestrate. Anecdotally, we know that passing games are generally viewed as more exciting which would favor White offensive coordinators.

The fact that White offensive coordinators manage more prolific passing offensives may mean that they are being used-or tasked-differently by their head coaches. This finding is also reflective of how quarterbacks were racial tasked (e.g., Whites passed and Black rushed), which would seem to indicate that racial tasking has permeated to the offensive coordinator position and that those individuals may be racially tasked as well. Considering the aforementioned hiring trend of administrators employing offensive-minded coaches, the fact that White offensive coordinators are leading more prolific passing offenses might make them prime candidates for vacant head coaching positions in which being able to score points through the air is a priority for those involved in the hiring process. Interestingly, there was no statistically significant difference in terms of total points scored in a season or overall total touchdowns between offensive coordinators based on race. This finding aligns with previous investigations of NFL coaches that found performance reward bias, lesser rewards for equivalent performance, generates racial disparity in leadership by suppressing the rate at which minorities, relative to equally-performing whites, are promoted to positions considered prerequisite for organizational leadership (Rider, Wade, Swaminathan, \& Schwab, 2016). In regards to point production and total touchdowns, Black offensive coordinators are succeeding at a level comparable to their White counterparts, yet not receiving the same rewards. 
In summary, based on our findings, racial tasking might serve to explain the formation of existing prejudices toward a Black coach's capabilities, both mental and physical, to perform. The performance of Black coaches compared with their White counterparts has not favored Black coaches which may create prejudices regarding their abilities to successfully perform in the position. White coaches are winning more games and lasting longer at their institutions, which may have a shared relationship. The lack of success of Black head coaches, coupled with their short tenures at the institutions that hire them, supports the idea that administrators may use or view Black and White coaches differently based on race.

\section{Implications}

This research offers several implications for future researchers and practitioners to consider. One is that there is a need for organizations, like the former BCA, to conduct research and advocate for the advancement of Black coaches. The plateau effect in recent coaching hires supports the notion that advocacy groups make a difference coaching advancement for minorities. Another implication of our study, adopting a suggestion from Harrison and Bukstein (2014), is that there is a need to make the hiring process for college football head coaches more transparent which could be accomplished with an instrument or scorecard called the "Transparent Performance Scale" that might encompass key components that answer the question of what aspects are most important in terms of a person becoming a head coach in the college football. The literature provides evidence that Black coaches are not being given many opportunities to be hired as head coaches or offensive coordinators (Bopp \& Sagas, 2012, Lapchick \& Baker, 2016). This study adds to that literature with findings that suggest, through racial tasking, the continued existence of racial biases or prejudices against Black coaches. Studies exploring the hiring practices of athletic administrators would be very useful in identifying where and how these biases or prejudices against Black coaches have formed.

\section{Future Research and Limitations}

The primary limitations of this study include the fact that we do not have information from athletic administrators regarding their hiring criteria, that we did not control for potential nonperformance biases that have led to the dismissal of head coaches, and that the researchers cannot say for certain that a head coach or offensive coordinator is solely responsible for their output numbers. In reference to the latter, this is because assistants, players, and a multitude of external factors all potentially play a role in that coach's success. Assistant coaches leaving for new jobs, player injuries, changes in the athletic administration, and the culture surrounding a coach's program all may influence the amount of wins he has or the way that the offense will play. Controlling for injuries to key players, or determining whether a coach was forced out because new administrators wanted to hire his or her own coach might strengthen the argument that race discrimination occurs at the head coaching level in college football.

However, this limitation also steers us toward a discussion that speaks to the very nature of this study: the existence of latent stereotypical assumptions, based 
on race (i.e., racial tasking of coaches), which potentially hinder the development and career expectations and aspirations of Black coaches. If administrators are hiring offensive minded assistant coaches, and the available talent pool of assistant coaches does not contain a lot of Black coaches, then it would be hard to make a claim that administrators are intentionally being racist in their hiring practices. Of course we should remember, based on the results of this study, that Black head coaches are being given a year less than their White counterparts and Kopkin's (2014) assertion that if decision makers are discriminating against Black head coaches when deciding whether to retain them, these racial attitudes are likely present in hiring decisions as well.

The researchers propose five recommendations for future research. The first is to survey position coaches that want to be offensive coordinators, and offensive coordinators that want to be head coaches, to determine if they perceive any barriers to upward mobility. A second recommendation is to develop programming-like coaching fellowships-designed to assist Black coaches in attaining desired positions as suggested by pervious researchers (Agyemang \& DeLorme, 2010). Our third recommendation, in agreement with Welty-Peachey (2015) and Melton (2015), is that scholars need to investigate what would motivate athletic departments to engage in social change work and activism. Social change actions like the Eddie Robinson Rule have little chance of being successful if athletic departments fail to find a reason to join the movement. In addition, as Harrison and Bukstein (2014) have suggested there is a need to develop and implement bias-lessening processes and procedures with respect to the hiring processes.

Our fourth recommendation is that future researchers should - to adequately determine the success of Black head coaches - compare their records at the institutions that hire them to the previous coaching regimes. If Black head coaches have not been successful at programs that have traditionally done poorly their records may not be an honest reflection of their coaching abilities, and it may mean that Black head coaches are accepting positions that would be categorized as Glass Cliff openings. Our fifth suggestion, serving as a call to extend the tasking literature, would be to encourage researchers to investigate how tasking may contribute to the lack of women, LGBT members, or other subjugated groups in sport. In reference to women, the TIDES college report found women held only $38.9 \%$ of the head coaching jobs of women's teams in Division I, 35.4\% in Division II and $43.8 \%$ in Division III (Lapchick \& Baker, 2016). Tasking can lead to a lack of opportunities and/or experiences that those in minority groups need to be successful.

\section{References}

Agyemang, K., \& DeLorme, J. (2010). Examining the dearth of Black head coaches at the NCAA football bowl subdivision level: A critical race theory and social dominance theory analysis. Journal of Issues in Intercollegiate Athletics, 3, 35-52.

Barnett, Z. (2015, January 29). The top 13 trends from the FBS coaching carousel. Retrieved from http://footballscoop.com/news/coaching-hirings-trends/

Big Ten Network. (2015, October, 11). Maryland's Randy Edsall fired-Press conference [Video file]. Retrieved from https://www.youtube.com/watch?v=wXIXzDdInts

Bopp, T., \& Sagas, M. (2012). An examination of Black NCAA DI-FBS football coaches: A five-year update. Journal of Intercollegiate Sport, 5, 153-169. doi:10.1123/jis.5.2.153 
Bopp, T., \& Sagas, M. (2014). Racial tasking and the college quarterback: Redefining the stacking phenomenon. Journal of Sport Management, 28(2), 136-142. doi:10.1123/ jsm.2012-0296

Branham, D. (2008). Taking advantage of an untapped pool: Assessing the success of Black head coaches in the National Football League. The Review of Black Political Economy, 35, 129-146. doi:10.1007/s12114-008-9031-1

Brescoll, V.L., Dawson, E., \& Uhlmann, E.L. (2010). Hard won and easily lost: The fragile status of leaders in gender-stereotype-incongruent occupations. Psychological Science, 21(11), 1640-1642. PubMed doi:10.1177/0956797610384744

Cunningham, G. B. (2003). Already aware of the glass ceiling: Race-related effects of perceived opportunity on the career choices of college athletes. Journal of African American Studies, 7(1), 57-71.

Cunningham, G.B. (2008). Commitment to diversity and its influences on athletic department outcomes. Journal of Intercollegiate Sport, 1(2), 176-201. doi:10.1123/jis.1.2.176

Cunningham, G.B., \& Bopp, T. (2010). Race ideology perpetuated. Journal of Sports Media, 5(1), 1-19. doi:10.1353/jsm.0.0048

Cunningham, G.B., Bruening, J.F., \& Straub, T. (2006). The Underrepresentation of Blacks in NCAA Division I-A head coaching positions. Journal of Sport Management, 20(3), 387-413. doi:10.1123/jsm.20.3.387

Cunningham, G.B., \& Sagas, M. (2005). Access discrimination in intercollegiate athletics. Journal of Sport and Social Issues, 29, 148-163. doi:10.1177/0193723504271706

Cunningham, G. B., Sagas, M., \& Ashley, F. B. (2001). Occupational commitment and intent to leave the coaching profession: Differences according to race. International Review for the Sociology of Sport, 36(2), 131-148.

Day, J.C. (2015). Transitions to the top: Race, segregation, and promotions to executive positions in the college football coaching profession. Work and Occupations, 42(4), 408-408. doi:10.1177/0730888415580651

Dodd, D. (2015, October 25). Greg Schiano leads 12 candidates to replace Al Golden at Miami. Retrieved from http://www.cbssports.com/collegefootball/writer/dennis-dodd/25353625/ greg-schiano-leads-list-of-12-candidates-to-replace-al-golden-at-miami.

Eagly, A.H., \& Karau, S.J. (2002). Role congruity theory of prejudice toward female leaders. Psychological Review, 109, 573-598. PubMed doi:10.1037/0033-295X.109.3.573

Eitzen, D.S. (2014). Sport in contemporary society: An anthology (10th ed.). New York, NY: Oxford University Press.

Everhart, B.C., \& Chelladurai, P. (1998). Gender differences in preferences for coaching as an occupation: The role of self-efficacy, valence, and perceived barriers. Research Quarterly for Exercise and Sport, 68, 188-200. PubMed doi:10.1080/02701367.199 8.10607683

Everhart, C.B., \& Chelladurai, P. (2004). Racial differences in coaching self-efficacy, occupational valence, and perceived barriers. International Journal of Sport Management, $5(1), 1-31$.

Finch, B., McDowell, J., \& Sagas, M. (2010). An examination of racial diversity in collegiate football: A 15 year update. Journal for the Study of Sports and Athletes in Education, 4(1), 47-57. doi:10.1179/ssa.2010.4.1.47

Forde, P. (2015, January 20). Biggest winners and losers from the college football coaching carousel. Retrieved from http://sports.yahoo.com/news/biggest-winners-and-losersfrom-the-college-football-coaching-carousel-065221084-ncaaf.html

Frankovelgia, C. (2010, April 28). The key to effective coaching. Retrieved from http://www. forbes.com/2010/04/28/coaching-talent-development-leadership-managing-ccl.html

Gemmell, K. (2012, November 26). Jon Embree fired by Colorado. Retrieved from http:// espn.go.com/college-football/story/_/id/8675463/jon-embree-fired-colorado-twoseasons 
Harrison, C.K. \& Bukstein, S. (2014). NFL occupational mobility patterns (volume III). A report for the NFL diversity and inclusion "good business" series.

Harrison, C.K., \& Yee, S. (2009). Protecting their turf: The head football coach hiring process, and the practices of FBS \& FCS colleges and universities. Report submitted for the Black Coaches and Administrators. Indianapolis, Indiana: BCA.

Hughes, A., \& Wright, M.W. (2003). Black men can’t coach? Black Enterprise, 33(12), 63-70.

Kamphoff, C., \& Gill, D. (2008). Collegiate athletes' perceptions of the coaching profession. International Journal of Sports Science \& Coaching, 3, 55-72. doi:10.1260/174795408784089351

Kopkin, N.A. (2014). You're fired! The impact of race on the firing of Black head coaches in major college football. The Review of Black Political Economy, 41(4), 373-392. doi:10.1007/s12114-014-9195-9

Lapchick, R. (2010). The effect of the economic downturn on college athletes and athletic departments on issues of diversity and inclusion. Journal of Intercollegiate Sport, 3(1), 81-95. doi:10.1123/jis.3.1.81

Lapchick, R., Anjorin, R., \& Nickerson, B. (2012). Striving for sustained positive change: The Black Coaches and Administrators (BCA) hiring report card for NCAA FBS and FCS football head coaching positions (2011-12). Report submitted for the Black Coaches and Administrators. Orlando, Florida: BCA.

Lapchick, R., \& Baker, D. (2016). The 2015 racial and gender report card: College sport. Retrieved from University of Central Florida, The Institute for Diversity and Ethics in Sport website: http://www.tidesport.org/

Madden, J.F., \& Ruther, M. (2011). Has the NFL's Rooney Rule efforts "leveled the field" for Black head coach candidates? Journal of Sports Economics, 12(2), 127-142. PubMed doi:10.1177/1527002510379641

Medcalf, M. (2016, February 4). Proposed Eddie Robinson rule would lead to more chances for minority candidates. Retrieved from http://espn.go.com/college-sports/story/_/ $\mathrm{id} / 1453$ 0019/national-association-coaching-equity-development-proposes-eddierobinson-rule-requiring-interviews-minority-candidates

Melton, E.N. (2015). Creating social change in and through intercollegiate sport. Journal of Intercollegiate Sport, 8(1), 1-13. doi:10.1123/jis.2015-0017

NCAA. (2016). NCAA champion forum. Retrieved from http://www.ncaa.org/about/ resources/ leadership-development-programs-and-resources/ncaa-champion-forum

O'Bryant, C. (2010). Will this recession undermine diversity and inclusion in sports? Journal of Intercollegiate Sport, 3(1), 101-110. doi:10.1123/jis.3.1.101

Olson, M. (2014, January 8). Red McCombs bashes Texas hire. Retrieved from http://www. espn. com/college-football/story/_/id/10257706/booster-red-mccombs-bashes-texaslonghorns-charlie-strong-hire

Park, S.R., Tomasini, N., \& Shields, J.W. (2010). Perceived opportunities and barriers to employment in the football coaching profession: Differences between NCAA Division I-A Black and White football student-athletes. International Journal of Applied Sport Sciences, 22(1), 33-58.

Rider, C. I., Wade, J., Swaminathan, A., \& Schwab, A. (2016). Racial disparity in leadership: Performance-reward bias in promotions of national football league coaches. Social Science Research Network 2710398.

Ryan, M.K., \& Haslam, S.A. (2005). The glass cliff: Evidence that women are over-represented in precarious leadership positions. British Journal of Management, 16, 81-90. doi:10.1111/j.1467-8551.2005.00433.x

Ryan, M.K., Haslam, S.A., Hersby, M.D., \& Bongiorno, R. (2011). Think crisis-think female: The glass cliff and contextual variation in the think manager-think male stereotype. The Journal of Applied Psychology, 96(3), 470-484. PubMed doi:10.1037/a0022133 
Sack, A.L., Singh, P., \& Thiel, R. (2005). Occupational segregation on the playing field: The case of Major League Baseball. Journal of Sport Management, 19, 300-318. doi:10.1123/jsm.19.3.300

Singer, J.N., Harrison, C.K., \& Bukstein, S.J. (2010). A critical race analysis of the hiring process for head coaches in NCAA college football. Journal of Intercollegiate Sport, 3(2), 270-296. doi:10.1123/jis.3.2.270

Smith, C. (2012, March 3). Hired guns: How search firms are changing the business of college coaching. Retrieved from http://www.forbes.com/sites/chrissmith/2012/03/30/ hired-guns-how-search-firms-are-changing-the-business-of-college-coaching/

Vannini, C. (2015, November 18). Rocky Long: People think a shiny new coach will fix everything. Retrieved from http://coachingsearch.com/article?a=Rocky-Long-Peoplethink-a-shiny-new-coach-will-fix-everything

Vito, B. (2015, October 19). Villarreal: UNT wants offensive-minded coach. Retrieved from http://www.dentonrc.com/sports/sports-headlines/20151019-villarreal-unt-wantsoffensive-minded-coach.ece

Welty Peachey, J. (2015). Creating social change in and through intercollegiate sport: State of the field, challenges, and future directions. Journal of Intercollegiate Sport, 8(1), 96-105. doi:10.1123/jis.2015-0024

Wong, E. (2002). The mystery of the missing minority coaches. Retrieved from http://www. nytimes.com/2002/01/06/weekinreview/06WONG.html 